\title{
An Application of Response Surface Method in the Optimization of Sheet Metal Blanking Process
}

\author{
Galal Mohamed Elkharraz \\ (Department of Industrial and Manufacturing system Engineering, University of Benghazi, Libya)
}

\begin{abstract}
The blanking process used in the manufacturing industry constitutes the first stage of any forming process, which is a widely used process in high volume production of sheet metal components. The main problem faced designers is the selection of an optimum combination of input variables to achieve the desired quality of blanked parts with minimum force. In order to overcome this problem, an effective planning and execution of precisely designed experiments utilizing the power of statistical analysis techniques are used. A Response Surface Method (RSM) was used for the purpose of building a statistical model relating the shearing force (response) to the selected process parameters; tool clearance, height shear angle and punch velocity. The objective of such a model was to enhance the understanding of this relationship and to allow the prediction of the blanking force through the given combination of the input process variables. In addition, the model was used to obtain the optimum combination of the input process variables yielding the minimum blanking force. The results were analyzed using the computer software (MINITABTM, and STATISTICA) and an initial regression model was obtained and refined after performing some appropriate significance tests on the regression coefficients. The refined model was then validated using some regression analysis techniques such as: normal probability plot, lack of fit test and goodness of fit measures. The effects of individual blanking variables and their significant interactions on the response were also investigated. It can be stated that the RSM approach provides a good contribution towards the optimization of sheet metal blanking process.
\end{abstract}

Keywords: Blanking process parameter; Central Composite Rotatable Design (CCRD); RSM; Shearing force; Statistical model

\section{Introduction}

Metal blanking is a widely used process in high volume production of metal components. General guidelines for this process exist but they are not sufficient to overcome the difficulties in designing blanking processes, where requirements for less cycle time and accurate product dimensions become more demanding. The design of blanking processes in industrial practice is still based largely on experimentations and it is often governed by time-consuming and expensive trial and-error iterations caused by limited, mostly empirical, knowledge of these processes. A new method that allows for the reduction of trial and error option in designing a blanking process is needed. Therefore, appropriate modeling and understanding of the blanking process could be beneficial to reduce the lead-time and to control the product specifications, especially the shape of a blanked (sheared) edge.

The blanking force is a dominant factor in the blanking process, as a cost-related response. A minimum punch force is desired because the higher the punch force the greater the amount of wear on the tooling. This is a critical issue in industry where expensive tooling for complicated components cannot be replaced on a regular basis [1]. In addition, in blanking processes, it is necessary to estimate the maximum force that can be used to select the correct press or decide whether the existing one is suitable. This information can be considered as a precursor to estimating the final cost of the machine [2].

The present work aims to study the effect of some blanking process parameters on the blanking force. A statistical model has been developed to estimate the optimum blanking force required (response) given a set of selected process parameters (input variables) namely; punch geometry (G), die-punch clearance (C), and punch velocity (V). An experiment has been designed based on Central Composite Rotatable Design (CCRD).

This design requires minimum experimental data sufficient to establish a second-order polynomial relating the response to the independent variables.

The developed model was analyzed and refined by testing the significance of the regression coefficients. The effects of individual selected process parameters and their significant interactions on the blanking force were studied and presented graphically. Contour plots and 3-dimensional response surface diagrams were drawn to visualize their nature.

\subsection{Blanking process}

Blanking is a manufacturing operation as old as the technology itself. Its applications range from components of very light to heavy appliances and machineries [3]. Blanking is defined as the cutting of a work 
piece between two die components to a predetermined contour [4]. Blanking process can be considered to include series of phases in which sheet metal undergoes deformation and separation as shown in Fig. 1[2]

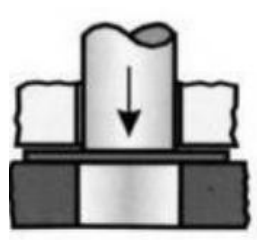

Contact of the punch

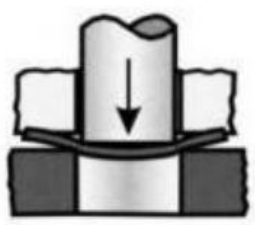

Elastic and plastic deformation

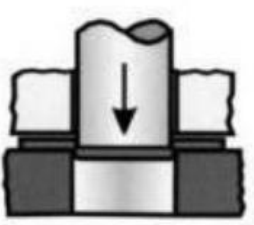

Shearing and crack formation

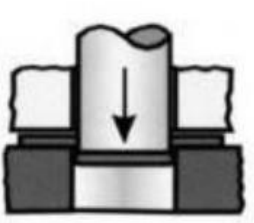

Breakthrough

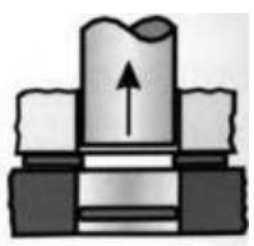

Stripping

Figure 1 Step of Blanking process

\subsubsection{Contact of punch}

The punch first touches the fixed sheet at impact a compressive stress rapidly builds on the punch and sends a shock wave through it.

\subsubsection{Elastic and plastic deformation}

The punch penetrates into the sheet .first causing an elastic and then plastic deformation

\subsubsection{Shearing and crack formation}

When the stresses increase shearing occurs followed by fracture .fracture begins from both the punch end and die end of the sheet they usually meet and complete fracture of the material takes place

\subsubsection{Breakthrough}

If the sheet material has a high strength or is thick a large force is required for blanking process. During fracture compressive forces are stored in the tool. When complete fracture occurs there is an instant release of the compressive forces these generate shock, which can lead to breakage of the punch in some cases.

\subsubsection{Stripping}

The punch move down to the bottom dead centre and ejects the part.

Several researches have emphasized different aspects of the blanking process. Through literature, it is clear that many methods are used to study the blanking process to achieve the optimal combination of its parameters. This includes analytical approaches [6, 7]; Finite Element Method [8, 9, and 10]; Design of Experiments [1,10] and Neural Networks Modeling [11]. Literature shows that the mechanical characteristics of the blanking process and the geometrical aspect of the sheared edge are affected by different parameters. These parameters include clearance, wear state of the tool, tool radii and geometry, thickness of the sheet, blank geometry, or layout, material prosperities such as hardness and ductility, friction, tools surface finish or lubricant type, sheet metal coating, and stroke rate or blanking speed [1,10 and 17]. Using a combination of techniques in analyzing the blanking process and its parameters and conducting comparisons are widely common in literature. Klingenberg and Singh [12] have compared two existing analytical models of blanking while Biglari et al. [13] have performed a comparison between fine and conventional blanking. Hambli [10] has combined predictive finite element approach with neural network modeling of the leading blanking parameters in order to predict the burr height of the parts for variety of blanking conditions. Brokken et al. [14] presented a set of interrelated numerical techniques resulting in a finite element model of the metal blanking process, focusing on the prediction of the shape of the cut edge of the blanked product. In addition, Rachik et al. [15] presented a comprehensive experimental and numerical study of the sheet metal blanking process. The clearance impact on the blanking processes has consumed a significant amount of research. This concern about the clearance factor is because the structure of the blanked surfaces is influenced by both the tooling (clearance and tool geometry) and the properties of the work piece material (blank thickness, mechanical properties, microstructure, etc.). The selection of the clearance influences the life of the die or punch, the blanking force, the unloading force and the dimensional precision [16]. Marouani et al. [17] studied the effect of punch velocity and punch and die clearance on the shearing process using experimental and numerical investigations. They concluded that both the maximum blanking force and the shape of the cut edge are influenced by the punch velocity. Additionally, they reported that numerical simulation was a useful tool not only to improve the process, but also to describe the material elastic-plastic behaviour during punching and to assess tool changes. Singh et al. [18] evaluated the effect of tool geometry on blanking force and deformation of the punch. However, it can be noted that there are few studies in the literature on punching or blanking of thick sheets using numerical simulation -despite the process being used industrially. Amol Totre et al [19] studied the factors affecting in the blanking process namely; Clearance, tool wear, sheet thickness and material, punch geometry 
Also they showed what are importance of this factors in the blanking process out of which clearance, thickness $\&$ tool wear is important factors clearance value of the various material

\subsection{Response surface methodology}

Response surface Methodology (RSM) is a set of statistical and mathematical approaches as is functional for developing, improving and optimizing processes [3]. It also has importance and applications in the design, development and formulation of new products, as well as in the improvement of exiting product design [4]. It is a good tool to explore the relationship between input variables and the performance measure or quality characteristics of the product or process [1].

In the blanking process, experimental design is considered a powerful technique for product and process development, and for improving the yield and stability of an ongoing process. Numerous research activities have been carried out in optimizing blanking parameters using design of experiment.

Hambli et al., [1] studied the effect of punch-die clearance and punch geometries on shearing force using RSM. They used four materials for testing with four different elongations (30\%, 47\%, 58\%, and $65 \%$ ). They showed that the optimum clearance decreases as the material elongation increases. The results of the proposed experimental investigation show that there is no universal optimal clearance value. They found that the design of experiments technique is an efficient and cost-effective way to model and analyze the relationships that describe process variations. .Emad and Ibrahim (2008), Represented a model investigate the effect of potential parameters influencing the blanking process and their interactions using Finite Element and RSM. The combination of both techniques is proposed to result in a reduction of the necessary experimental cost and effort in addition to getting a higher level of verification. It can be stated that the Finite Element Method coupled with RSM technique provided a good contribution towards the optimization of sheet metal blanking process. They use Design of Experiments (DOE) technique by selecting the experimental levels for each selected factor, i.e., the clearance to be in five levels $(5 \%, 10 \%, 15 \%, 20 \%, 25 \%)$ of the sheet metal thickness, blank holder force to be in two levels $(0,3000 \mathrm{~N})$ and sheet metal thickness to be in four levels $(0.5 \mathrm{~mm}, 0.6 \mathrm{~mm}, 0.7 \mathrm{~mm}, 0.8 \mathrm{~mm})$. Perform a factorial experimental design in order to take high-level interactions. Develop a Finite Element Model (FEM) that represents the existing process in order to evaluate the quality of the inputs. Compare the two techniques (FEM and DOE) and analyze the results to get the proposed optimal set of parameters. They show that, in order to minimize the burrs height, the clearance should be set at about $5 \%$ with almost no blank holder force.

T.Z.Quazi, et al (2013) evaluated the influence of tool clearance, sheet thickness and sheet material thus optimizing clearance which affects other process parameters. The designs of experiments (DOE) technique by Taguchi method was used in order to achieve the intended model objectives. The investigation showed that the clearance should be set at about $5 \%$ with almost no blank holder force to minimize the burr height. The presented investigation of the blanking process makes it possible to predict optimum process parameters. The authors stated that the Design of Experiments technique can be used in order to contribute towards the optimization of sheet metal blanking processes. Rahul Nishad et al, 2013 showed the different methodologies used for the prediction of the optimum parameters involved in the sheet metal blanking process and optimization of these parameters. The different parameters that control the output of the process have been studied in detail and their effect on the quality of the blanked material is analyzed using different methodologies. It was found that Design of experiments technique helps to find the most effective parameter leading towards optimal combination of parameters setting.

The process modeling by response surface methodology (RSM) using statistical design of experiments based on central composite design is proved to be an efficient modeling tool. The methodology not only reduces the cost and time but also gives the required information about the main and interaction effects. In this study, a second-order response surface (RSM) model for predicting shearing force of Blanked specimens made of low carbon steel is developed.

\section{Experimental Work}

The experimental work has been conducted according to the following procedures:

\subsection{Identification of the Process Parameters}

A summary of the blanking parameters with their classification is presented in Fig. 2. The identified controllable parameters are Punch geometry $(\mathrm{G})$, die-punch clearance $(\mathrm{C})$ and Blanking speed $(\mathrm{S})$ whereas, the uncountable parameters are material thickness, blank holder force and punch-die alignment. 


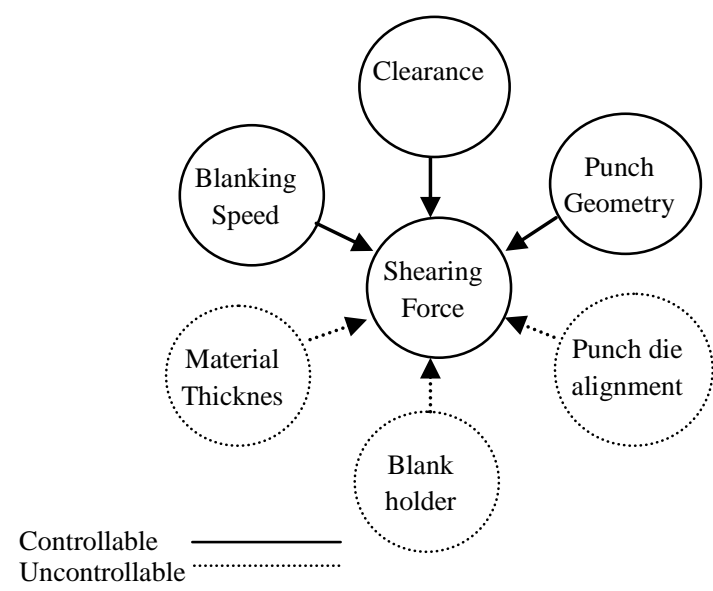

Figure 2. Summary of the blanking parameters situation in this research

\subsection{Working Ranges of Process Parameters}

The working range of each parameter (Table 1) represents the boundaries of the optimum region to be searched. These ranges were based on the recommended optimum ranges of both the clearance and the height shear angle $[2,3,4,7-15]$ that would contribute to a good edge surface of the blanked part. The universal testing machine limitation requires the punch velocity to be in the range $0-250 \mathrm{~mm} / \mathrm{min}$. The selected range is $30-150$ $\mathrm{mm} / \mathrm{min}$ due to some limitations of the machine used.

Table 1: working ranges of the selected parameters.

\begin{tabular}{|l|c|c|c|}
\hline \multirow{2}{*}{ Parameter } & \multirow{2}{*}{ Notation } & \multicolumn{2}{|c|}{ Working range } \\
\cline { 3 - 4 } & $\mathrm{C}$ & $3 t$ & $19 t$ \\
\hline Tool Clearance & $\mathrm{H}$ & 0 & $2 t$ \\
\hline Height Shear Angle & $\mathrm{V}$ & $\begin{array}{c}30 \\
\mathrm{~mm} / \mathrm{min}\end{array}$ & $\begin{array}{c}150 \\
\mathrm{~mm} / \mathrm{min}\end{array}$ \\
\hline Punch velocity & &
\end{tabular}

Where:- $\mathrm{t}$ is sheet metal thickness

\subsection{The Levels of Each Process Parameter}

Based on Central Composed Rotatable Design, the experimental levels for each parameter have been identified. These levels are coded as $(-1.682,-1,0,+1$, and +1.682$)$ as shown in Table 2 . The first and last codes are computed according to equation (1):

Where $\mathrm{k}=$ number of parameters.

$$
\alpha=2^{\frac{k-1}{4}}
$$

The original values (y) can be calculated based on equation (2):

$$
\mathrm{y}=\mathrm{y}_{\text {min }}+\frac{\mathrm{x}+1.682}{3.364}\left(\mathrm{y}_{\text {max }}-\mathrm{y}_{\text {min }}\right)
$$

Where $y$ is the original value of the parameter, $x$ is the coded value of $y$, ymax is the upper level of $y$, and ymin is the lower level of $y$. These values are shown in Table 2

\begin{tabular}{|c|c|c|c|c|c|}
\hline \multirow{2}{*}{ Parameter } & \multicolumn{5}{|l|}{ Levels } \\
\hline & -1.682 & -1 & 0 & 1 & 1.682 \\
\hline $\begin{array}{l}\text { Clearance, C } \\
(\mathrm{mm})\end{array}$ & 0.045 & 0.093 & 0.165 & 0.236 & 0.285 \\
\hline $\begin{array}{l}\text { Height shear angle, } \mathrm{H} \\
(\mathrm{mm})\end{array}$ & 0 & 0.608 & 1.5 & 2.39 & 3 \\
\hline $\begin{array}{l}\text { Punch velocity, V } \\
(\mathrm{mm} / \mathrm{min})\end{array}$ & 30 & 55 & 90 & 125 & 150 \\
\hline
\end{tabular}

Table 2: process control parameters and their levels. 


\subsection{Construction of the Experimental Design Matrix}

The matrix shown in Table 3, is based on a central composite rotatable, fixed level, uniform precision design. 20 sets of coded combinations were used with full replication of $8\left(2^{3}\right)$ factorial point plus six center points and six extreme points. This design matrix will lead to the estimation of the linear, quadratic and interaction effects of the process parameters on the blanking force.

\subsection{Conducting the Experiments and Recording the Response}

Experiments were carried out under the following conditions:

- Sheet metal thickness (t) of $1.5 \mathrm{~mm}$,

- Die diameter of $50 \mathrm{~mm}$,

- Sharp punch and die cutting edges,

- $\quad$ Lubrication with emulsion, type "PLATINOL W4", and

- Stripping force application obtained by trial and error.

The observed blanking force (response) was measured using both the force transducer of the testing machine and punch force displacement plotter. These observed values are shown in Table 3.

Table 3: experimental design matrix and observed values.

\begin{tabular}{|c|c|c|c|c|r|}
\hline Run No. & Random Rank & X1 & X2 & X3 & Y(KN) \\
\hline 1 & 1 & -1 & -1 & -1 & $\mathbf{7 6 . 0 0}$ \\
\hline 2 & 14 & 1 & -1 & -1 & $\mathbf{6 0 . 0 0}$ \\
\hline 3 & 11 & -1 & 1 & -1 & $\mathbf{4 3 . 0 0}$ \\
\hline 4 & 4 & 1 & 1 & -1 & $\mathbf{3 8 . 0 0}$ \\
\hline 5 & 13 & -1 & -1 & 1 & $\mathbf{7 7 . 0 0}$ \\
\hline 6 & 8 & 1 & -1 & 1 & $\mathbf{6 2 . 0 0}$ \\
\hline 7 & 16 & -1 & 1 & 1 & $\mathbf{4 9 . 0 0}$ \\
\hline 8 & 2 & 1 & 1 & 1 & $\mathbf{4 4 . 0 0}$ \\
\hline 9 & 6 & -1.682 & 0 & 0 & $\mathbf{5 8 . 7 0}$ \\
\hline 10 & 12 & 1.682 & 0 & 0 & $\mathbf{4 3 . 0 0}$ \\
\hline 11 & 15 & 0 & -1.682 & 0 & $\mathbf{8 0 . 9 0}$ \\
\hline 12 & 20 & 0 & 1.682 & 0 & $\mathbf{3 6 . 8 0}$ \\
\hline 13 & 5 & 0 & 0 & -1.682 & $\mathbf{5 5 . 3 0}$ \\
\hline 14 & 9 & 0 & 0 & 1.682 & $\mathbf{5 6 . 1 0}$ \\
\hline 15 & 19 & 0 & 0 & 0 & $\mathbf{5 4 . 0 0}$ \\
\hline 16 & 10 & 0 & 0 & 0 & $\mathbf{5 4 . 6 0}$ \\
\hline 17 & 18 & 0 & 0 & 0 & $\mathbf{5 3 . 2 0}$ \\
\hline 18 & 7 & 0 & 0 & 0 & $\mathbf{5 8 . 0 0}$ \\
\hline 19 & 3 & 0 & 0 & 0 & $\mathbf{5 7 . 5 0}$ \\
\hline 20 & 17 & 0 & 0 & 0 & $\mathbf{5 2 . 0 0}$ \\
\hline & & & & & \\
\hline
\end{tabular}

\section{Results And Discussion}

The regression model was refined by applying statistical techniques such as significance tests, adequacy checks, and goodness of fit measures.

\subsection{Significance Tests}

The estimated coefficients of the developed regression model were tested for significance based on partial F-tests. Using a significance level $\alpha=0.05$, the final regression model was expressed as:

$$
\hat{Y}=
$$

$$
55.27-4.98 \mathrm{x}_{1}-12.87 \mathrm{x}_{2}+1.24 \mathrm{x}_{3}-1.25 \mathrm{x}_{1}^{2}+1.57 \mathrm{x}_{2}^{2}+2.7 \mathrm{x}_{1} \mathrm{x}_{2}
$$

\subsection{Model Validity}

\subsubsection{Checking the adequacy of the model}

The scatter plot in Fig. 3 indicates that the predicted values of the blanking force are in good agreement with the experimental values. This is supported by the high correlation coefficient $(R=0.99)$. 


\subsubsection{Lack of fit test}

The model was tested for lack of fit using the F-test and the results are shown in the Analysis of Variance (ANOVA) Table 4. The lack of fit component is not significant $(\alpha=0.05)$, thus the developed regression model adequately fits the experimental data.

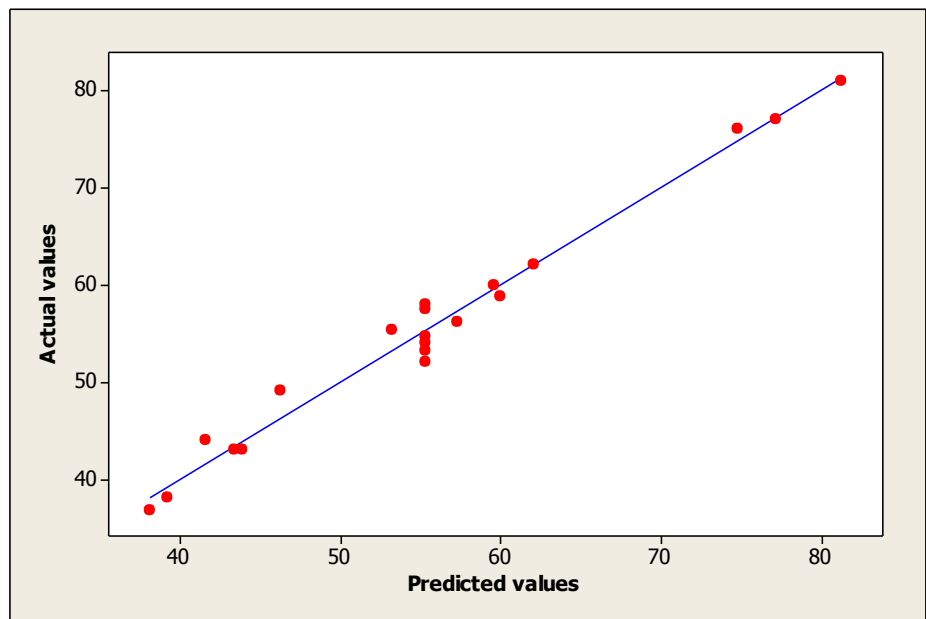

Figure 3: Scatter plots of the observed values vs. predicted values of the blanking force.

Table 4: ANOVA table showing lack of fit.

\begin{tabular}{|l|l|l|l|l|l|}
\hline Source & DF & SS & MS & F-values & P-values \\
\hline Regression & 6 & 2744.82 & 457.50 & 106.30 & 0.000 \\
\hline Linear & 3 & 2621.82 & 873.94 & 203.13 & 0.000 \\
\hline Quadratic & 2 & 64.68 & 32.34 & 7.52 & 0.007 \\
\hline Interaction & 1 & 58.32 & 58.32 & 13.56 & 0.003 \\
\hline Residual & 13 & 55.93 & 4.302 & & \\
\hline Lack of Fit & 8 & 27.36 & 3.42 & 0.60 & 0.753 \\
\hline Pure Error & 5 & 28.57 & 5.714 & & \\
\hline Total & 19 & 2800.75 & & & \\
\hline
\end{tabular}

\subsection{Goodness of Fit Measures}

The calculated coefficient of determination (R2) means that $98 \%$ of the variation in the blanking force (response) could be attributed to the selected process variables; hence the developed regression model is capable of accurate prediction of the blanking force.

The adjusted value of R2 (97\%) is very close to the R2 value. This indicates that the sample size and terms of the model are satisfactory.

\subsection{Effect Of Significant Process Parameters On The Response}

Based on the statistical model developed, the effect of the significant process parameters on the response were examined between the coded levels -1.682 and +1.682 . The main and interaction effects of these parameters on the response were plotted.

\subsubsection{The effect of clearance on the blanking force}

The tool clearance was varied at different levels, while keeping the punch velocity and the height shear angle constant at zero levels. It is evident that the blanking force is affected by the tool clearance as shown in Fig. 4. As the clearance decreases the blanking force increases. This is due to that the fracture lines do not meet together, causing a double shearing. 


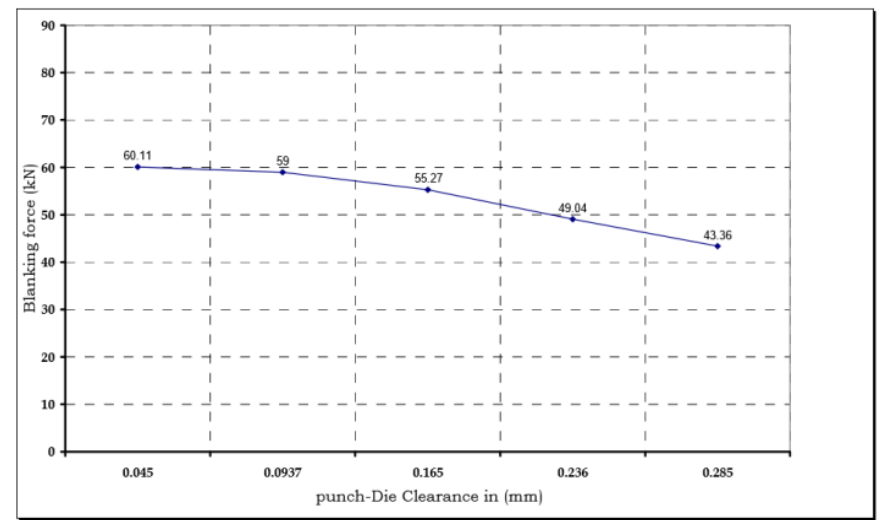

Figure 4: Effect of clearance $(\mathrm{C})$ on the blanking force.

\subsubsection{The effect of the height shear angle on the blanking force}

The height shear angle was varied at different levels, while keeping the punch velocity and tool clearance constant at zero levels. As shown in Fig. 5, the height shear angle increases as the applied blanking force decreases. This is expected as the shear angle causes progressive cutting with a minimum amount of cutting occurring at any instant of punch movement.

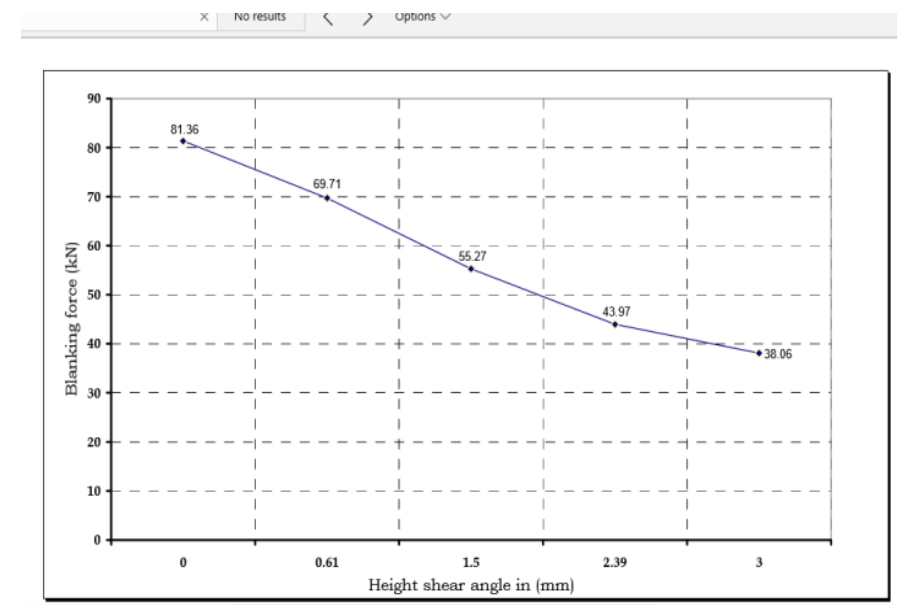

Figure 5: Effect of height shear angle $(\mathrm{H})$ on the blanking force.

\subsubsection{The effect of the punch velocity on the blanking force}

The punch velocity was varied at different levels, while keeping the tool clearance and the height shear angle constant at zero levels. As shown in Fig. 6, as the punch velocity increases the blanking force slightly increases. This may be due to the fact that the punch velocity is approaching zero before cutting occurs.

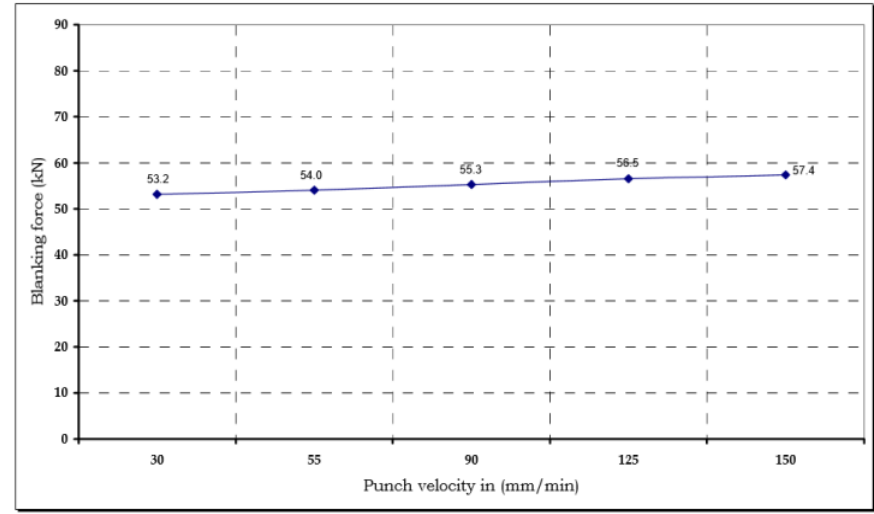

Figure 6: Effect of punch velocity (V) on blanking force 


\subsection{Response Surface Plots}

The main objective of the response surface plot is to determine the optimum operating conditions represented by the height shear angle, tool clearance and punch velocity which lead to the minimum blanking force required. The relation is represented as a solid surface in a three-dimensional space, where the blanking force is plotted versus the limits of the two selected input variables. The three-dimensional response surface plots, generated from the fitted model are shown in Fig. (7, 8 and 9).

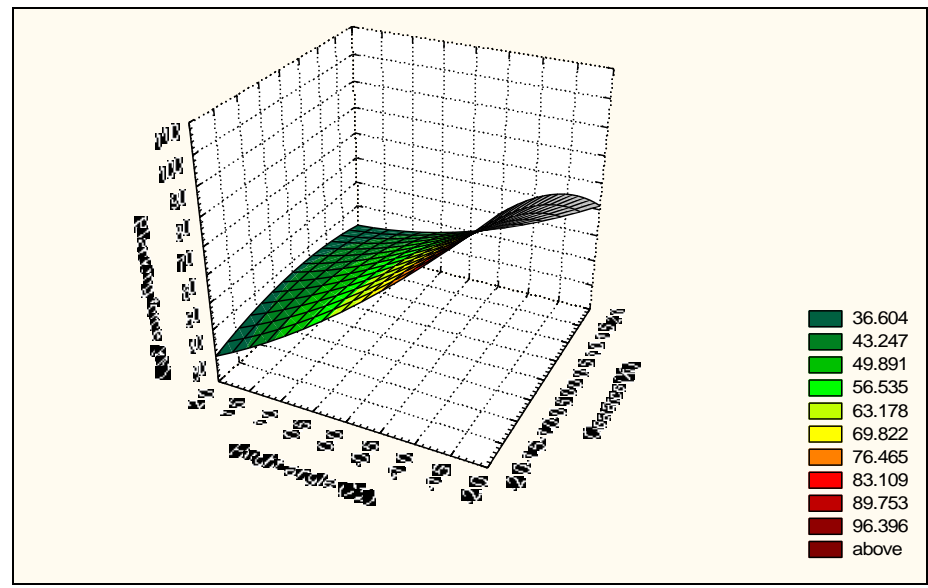

Figure 7: A three-dimensional response surface plot of the expected Blanking force (y) as a function of clearance $\left(\mathrm{x}_{1}\right)$ and Height shear angle $\left(\mathrm{x}_{2}\right)$ at constant punch velocity.

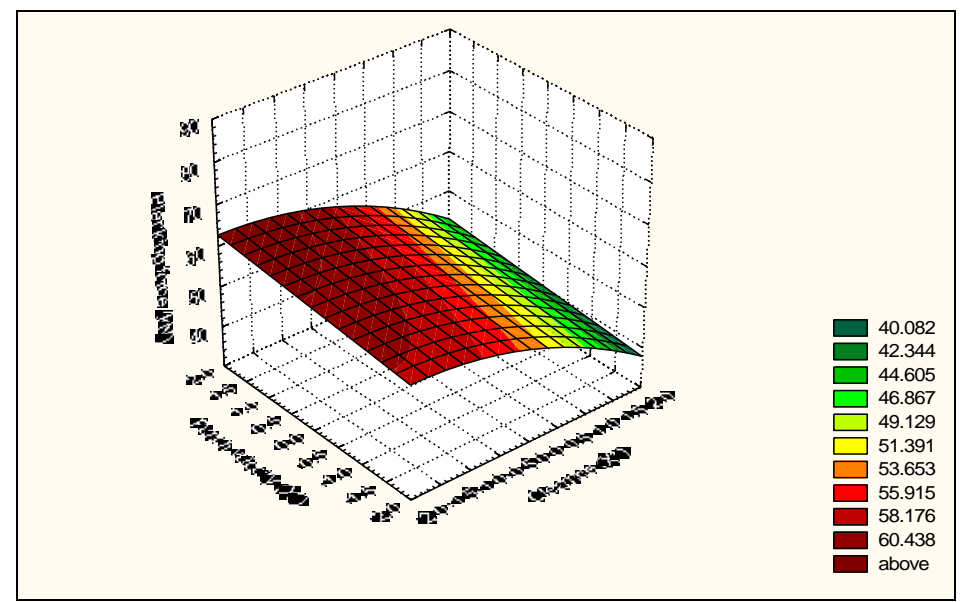

Figure 8: A three- dimensional response surface plot of the expected Blanking force (y) as a function of clearance $\left(\mathrm{x}_{1}\right)$ and punch velocity $\left(\mathrm{x}_{3}\right)$ at constant Height shear angle.

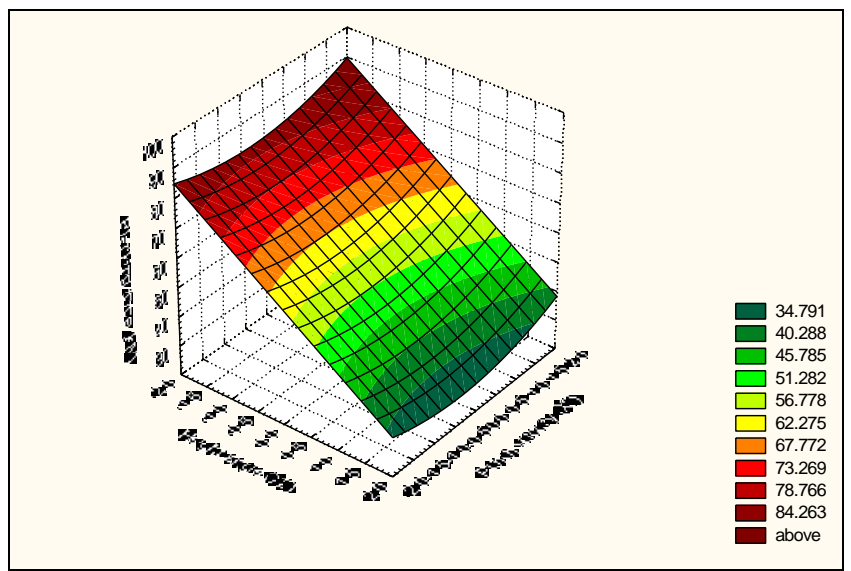

Figure 9: A three-dimensional response surface plot of the expected Blanking force (y) as a function of Height shear angle $\left(\mathrm{x}_{2}\right)$ and punch velocity $\left(\mathrm{x}_{3}\right)$ at constant clearance. 
By examining the response surface figures, the optimum regions of the response between $\mathrm{x} 1$ and $\mathrm{x} 2$, which represent the minimum blanking force values, can be identified and are shown in Table5.

Table 5: Optimum region of the response.

\begin{tabular}{|c|c|c|c|c|}
\hline $\begin{array}{c}\text { Figure } \\
\text { No. }\end{array}$ & $x_{1}(\mathrm{C})$ & $x_{2}(\mathrm{H})$ & $x_{3}(\mathrm{~V})$ & $\begin{array}{c}\text { Min. force } \\
(\mathrm{KN})\end{array}$ \\
\hline 6 and 7 & +1.682 & +1.682 & 0 & 33.78 \\
\hline 8 and 9 & +1.682 & 0 & -1.682 & 41.26 \\
\hline 10 and 11 & 0 & 1.682 & -1.682 & 35.9 \\
\hline
\end{tabular}

The above Table showed that the minimum force required is always achieved at the highest coded value of height shear angle (1.682), large clearance (1.682) and lowest punch velocity (-1.682).

Table 6 shows the optimum combination of process parameters height shear angle, clearance and punch velocity that yields the minimum blanking force.

Table 6: Optimum operation condition of blanking processes.

\begin{tabular}{|c|c|c|c|}
\hline Variables & Units & Limit code & Original value \\
\hline Clearance $(\mathrm{C})$ & $\mathrm{mm}$ & +1.682 & $0.19 \mathrm{t}$ \\
\hline Height shear angle $(\mathrm{H})$ & $\mathrm{mm}$ & +1.682 & $2 \mathrm{t}$ \\
\hline Velocity $(\mathrm{V})$ & $\mathrm{mm} / \mathrm{min}$ & -1.682 & 30 \\
\hline
\end{tabular}

\section{Conclusions}

A Central Composite Rotatable Design (CCRD) with full replication has been developed for the purpose of building a statistical model relating the blanking force (response) to selected process variables, namely; tool clearance, height shear angle and punch velocity.

The objective of such a model was to enhance the understanding of this relationship and to allow prediction of the blanking force using a combination of input process variables. In addition, the model utilized the Response Surface Method (RSM) to obtain the optimum combination of the input process variables yielding the minimum blanking force. The main conclusions are as follows:

- The height shear angle and clearance have the highest effect on the blanking force. The punch velocity, though statistically significant, has little effect on the blanking force.

- The blanking force decreases as the height shear angle and the clearance increase, while it increases as the punch velocity increases.

- The blanking force is most sensitive to changes in the height shear angle.

- The interaction effect of clearance and height shear angle on the blanking force was indicated by the gradual weakening of the relationship between clearances and blanking force as the height shear angle increased. This supports the previous point that when the shear angle is increased, it becomes a dominant factor affecting the blanking force.

- In addition to the prediction of the blanking force given a feasible combination of blanking variables (within the range studied), the model developed can also be used to determine the combinations required to achieve the desired blanking force.

- The Central Composite Rotatable Design (CCRD) proved to be successful in modeling the relationships between the blanking force and the different process variables; it requires a relatively small number of experiments which made it practical and economical to employ.

\section{References}

[1] R. Hambli R., "Design of experimental based analysis for sheet metal blanking processes optimization." The International Journal of Advanced Manufacturing Technology, vol. 19, 2002, pp. 403-410.

[2] Colgan M. and Monaghan J.," Deep drawing process: Analysis and Experiment." Journal of Materials Process Technology, vol. 132, 2003, pp. 35-41.

[3] Kalpakjian. S, Manufacturing Engineering and Technology. 3rd edition, New York: Addison Wesley, 1995

[4] Ostwakd P. and Munoz J., Manufacturing Processes and System, 9th edition, John Wiley\& Sons, 1997, Toronto.

[5] F. Faura., Sebastian and R. Zamora," A decision support system for sheet metal blanking process parameters selection." Journal of Materials Process Technology, vol. 118, 2001, pp. 371-376.

[6] R. Hambli, "Finite element model fracture predication during sheet-metal blanking processes." Engineering Fracture Mechanics, vol. 68,2001 , pp. $365-378$

[7] W. Klingenberg, and U. Singh, "Comparison of two analytical models of blanking and proposal of a new model". International Journal of Machine Tools and Manufacture, Vol. 45, 2005, 519-527.

[8] W. Klingenberg, and U. Singh, "Finite element simulation of the punching/blanking process using in-process characterization of mild steel". Journal of Materials Processing Technology, Vol. 134, 2003, 296-302

[9] R. Hambli, "BLANKSOFT: a code for sheet metal blanking processes optimization". Journal of Materials Processing Technology, Vol. 141, 2003, 234-242. 
[10] R. Hambli, S. Richir, P. Crubleau, and B. Taravel, "Prediction of optimum clearance in sheet metal blanking processes". International Journal of Advanced Manufacturing Technology, Vol. 22, 2003, 20-25

[11] R. Hambli, and F. Guerin, "Application of a neural network for optimum clearance prediction in sheet metal blanking processes". Finite Elements in Analysis and Design, Vol.39, 2003, 1039-1052.

[12] W. Klingenberg, and U. Singh, "Comparison of two analytical models of blanking and proposal of a new model". International Journal of Machine Tools and Manufacture, Vol. 45, 2005, 519-527.

[13] F. Biglari, A. Kermani, M. Parsa, K. Nikbin, and N. O'Dowd, "Comparison of fine and conventional blanking based on ductile fracture criteria". 7th Biennial ASME Conference on Engineering Systems Design and Analysis, Manchester, UK, 2004

[14] D. Brokken, W. Brekelmans, and F. Baaijens, "Predicting the shape of blanked products: a finite element approach". Journal of Materials Processing Technology, Vol.103, 2000, 51-56

[15] M. Rachik, J. Roelandt, and A. Maillard, "Some phenomenological and computational aspects of sheet metal blanking simulation". Journal of Materials Processing Technology, Vol. 128, 2002, 256-265.

[16] G. Fang, G., P. Zeng, and L. Lou, "Finite element simulation of the effect of clearance on the forming quality in the blanking process". Journal of Materials Processing Technology, Vol.122, 2002, 249-254.

[17] Marouani H, Ben Ismail A, Hug E, Rachik M. Numerical investigations on sheet metal blanking with high speed deformation. Material \& Design 2009;30:3566-3571

[18] U.P. Singh, A.H. Streppel and H.J.J. Kals "Design study of the geometry of a punching/blanking tool", Journal of Materials Processing Technology, 33, 331345, (1992)

[19] Amol Totre, Rahul Nishad, Sagar Bodke," An Overview Of Factors Affecting In Blanking Processes". International Journal of Emerging Technology and Advanced Engineering, Vol 3,issue 3, 2013, 390-395

[20] Montgomery Douglas C., Design and Analysis of Experiments. 5th edition, John Wiley \& Sons, USA, 2001

[21] Emad Al-Momani, Ibrahim Rawabdeh, (Mar. 2008), "An Application of Finite Element Method and Design of Experiments in the Optimization of Sheet Metal Blanking Process" Jordan Journal of Mechanical and Industrial Engineering. Volume 2, Number 1, Pages $53-63$

[22] T.Z.Quazi, R. Shaikh, Amol Totre, Rahul Nishad,Sagar Bodke, Angad Chauhan,” Blanking process optimization using Taguchi method", International Journal of Engineering Research and Development, Volume 7, Issue 2 (May 2013), PP. 45-51

[23] Rahul Nishad1*, Amol Totre1, Sagar Bodke1 and Angad Chauhan,"An Overview Of The Methodologies Used In The Optimization Processes In Sheet Metal Blanking", international journal of mechanical engineering and robotic research, vol 2, No.2, 2013 